\title{
Microeconomic Analysis of Export Credit Program
}

\author{
N. Tungalag, R. Enkhbat*, Ch. Undram, Ch. Ankhbayar \\ National University of Mongolia, Ulaanbaatar, Mongolia \\ Email: `renkhbat46@yahoo.com
}

How to cite this paper: Tungalag, N., Enkhbat, R., Undram, Ch. and Ankhbayar, Ch. (2018) Microeconomic Analysis of Export Credit Program. iBusiness, 10, 177-184. https://doi.org/10.4236/ib.2018.104010

Received: September 6, 2018

Accepted: November 12, 2018

Published: November 15, 2018

Copyright $\odot 2018$ by authors and Scientific Research Publishing Inc. This work is licensed under the Creative Commons Attribution International License (CC BY 4.0).

http://creativecommons.org/licenses/by/4.0/

\section{(c) (i) Open Access}

\begin{abstract}
The aim of this paper is to study theoretical aspects of export credit insurance in the framework of microeconomics and analyze the economic impacts of an export credit program on trade flows within a framework of a microeconomic analysis. A multi-country trade model has been developed based on optimization methods and algorithm. For our theoretical analysis, we consider a multi-country trade model when one of countries imports an export good from other countries.
\end{abstract}

\section{Keywords}

Export, Import, Demand and Supply Function, Export Credit Insurance Program

\section{Introduction}

It is important for creating a multi-pillar economy to increase an export of final products absorbed with science, technology, innovation and knowledge.

There are both financial and non-financial instruments to diversify and support exports and one of the non-financial methods is to develop an export credit insurance.

The study found that 80 - 90 percent of the world's trade was based on loans and insurance guarantees [1]. From here, export credit insurance is an important instrument for managing risks, and the company has an opportunity to expand its foreign trade.

The "export credit insurance" is the guarantee of repayment of trade receivables in the form of insurance when exporter sells its goods on short-term loans.

The primary purpose of export credit insurance is to make commerce more accessible, mutually beneficial and less risky for businesses. 
In our theoretical model, we consider a multi-country trade model where one of countries imports its good from other countries. We assume that there is one tradable good, namely good $x$. The import demand and export supply functions are analyzed based on utility and profit maximization problems. We assume that there is no production in the importing country and no consumption in the exporting countries with regarding to the tradable good.

\section{Import Demand and Export Supply Functions}

Assume that the utility function of the importing country is represented by Cobb-Douglas function:

$$
U\left(x_{1}, x_{2}, \cdots, x_{n}\right)=A x_{1}^{\alpha_{1}} x_{2}^{\alpha_{2}} \cdots x_{n}^{\alpha_{n}}
$$

where, $\alpha_{i} \geq 0, \sum_{i=1}^{n} \alpha_{i} \leq 1, i=1,2, \cdots, n$.

$x_{i}$-quantity of export good $x$ from country $i, \quad i=1,2, \cdots, n$.

Consider the utility maximization problem subject to cost and demand constraints.

$$
\begin{gathered}
\max U\left(x_{1}, x_{2}, \cdots, x_{n}\right)=A x_{1}^{\alpha_{1}} x_{2}^{\alpha_{2}} \cdots x_{n}^{\alpha_{n}} \\
\sum_{i=1}^{n} p_{i} x_{i} \leq C \\
\sum_{i=1}^{n} x_{i} \leq A
\end{gathered}
$$

$p_{i}$-is a price per unit good for country $i$, where $C$ is budget, $A$ is a demand of the importing country.

Problem (1)-(3) is concave maximization problem for which Kuhn-Tucker optimality conditions [2] can be written in the following way.

$$
\left\{\begin{array}{l}
\frac{\partial L}{\partial x_{i}}=-\frac{\partial U}{\partial x_{i}}+\lambda_{1} p_{i}+\lambda_{2}=0, i=1,2, \cdots, n . \\
\lambda_{1}\left(\sum_{i=1}^{n} p_{i} x_{i}-C\right)=0, \\
\lambda_{2}\left(\sum_{i=1}^{n} x_{i}-A\right)=0 \\
\lambda_{1} \geq 0, \lambda_{2} \geq 0, \lambda_{1}+\lambda_{2}>0,
\end{array}\right.
$$

where $L$ is the Lagrange function,

$L=-U\left(x_{1}, x_{2}, \cdots, x_{n}\right)+\lambda_{1}\left(\sum p_{i} x_{i}-C\right)+\lambda_{2}\left(\sum x_{i}-A\right)$.

It is hard to solve the system (4) of nonlinear equations and inequalities. That is why in order to solve problem (1)-(3), we need to apply an optimization method, for instance, the conditional gradient method. Before we write the algorithm of this method, we introduce the following notation. Denote by $D$ a set of feasible solutions of problem (1)-(3).

$$
D=\left\{x \in R^{n} \mid \sum_{i=1}^{n} p_{i} x_{i} \leq C, \sum_{i=1}^{n} x_{i} \leq A, x_{i} \geq 0, i=\overline{1, n}\right\} .
$$

It is clear that the set $D$ is convex. Also, the gradient of the function $U$ is as follows:

$$
U(x)=\frac{\partial U}{\partial x}=\left(\frac{\partial U}{\partial x_{1}}, \frac{\partial U}{\partial x_{2}}, \cdots, \frac{\partial U}{\partial x_{n}}\right)
$$


where

$$
\frac{\partial U}{\partial x_{i}}=A x_{1}^{\alpha_{1}} x_{2}^{\alpha_{2}} \cdots\left(\alpha_{i} x_{i}^{\alpha_{i}-1}\right) \cdots x_{n}^{\alpha_{n}}, i=1,2, \cdots
$$

Now we are ready to formulate the algorithm of the conditional gradient method [2].

Algorithm CGM

Step 1. Choose a feasible point $x^{k}$ in $D, k:=0$.

Step 2. Compute the gradient of the function $U$ at $x^{k}$ by Formula (5).

Step 3. Solve the following linear programming problem

$$
\max _{x \in D}\left\langle U^{\prime}\left(x^{k}\right), x\right\rangle \text {. }
$$

Let $\bar{x}^{k}$ be a solution to this problem, i.e.

$$
\left\langle U^{\prime}\left(x^{k}\right), \bar{x}^{k}\right\rangle=\max _{x \in D}\left\langle U^{\prime}\left(x^{k}\right), x\right\rangle .
$$

Step 4. Denote by $\eta_{k}$ the value

$$
\eta_{k}=\left\langle U^{\prime}\left(x^{k}\right), \bar{x}^{k}-x^{k}\right\rangle .
$$

Step 5. If $\eta_{k}=0$. Then $x^{k}$ is a solution to problem (1)-(3) and stop. Otherwise, go to the next step.

Step 6. Construct the direction $h^{k}$ :

$$
h^{k}=\bar{x}^{k}-x^{k} .
$$

Step 7. Choose $\alpha_{k}$ from the condition

$$
\begin{gathered}
U\left(x^{k}+\alpha_{k} h^{k}\right)>U\left(x^{k}\right), \\
0<\alpha^{k}<1 .
\end{gathered}
$$

Step 8. Construct a next approximation point $x^{k+1}$ as

$$
x^{k+1}=x^{k}+\alpha_{k} h^{k} \text { and set } k:=k+1 \text {, go to step } 2 .
$$

A convergence of the algorithm is given by the following statement.

Theorem [2]. Assume that the gradient $U^{\prime}(x)$ satisfies the Lipschitz condition on $D$ with a constant $L$, i.e.

$$
\left\|U^{\prime}(x)-U^{\prime}(y)\right\| \leq L\|x-y\|, L>0, \forall x, y \in D
$$

Let $x^{0}$ be an arbitrary feasible point of $D$. Then a sequence $\left\{x^{k}\right\}$ constructed by Algorithm CGM converges to a solution of problem (1)-(3), that is

$$
\lim _{k \rightarrow \infty} U\left(x^{k}\right)=\max _{x \in D} U(x) .
$$

\section{Export Supply Function}

In order to obtain the supply function of the exporting country, we need to solve the profit maximization problem.

Assume that the firm of exporting country produces a single output $x_{i}$ using several inputs. Suppose that their short-run variable costs are defined as a cubic function of the form. 


$$
c_{i}\left(x_{i}\right)=a_{i} x_{i}^{3}+b_{i} x_{i}^{2}+c_{i} x_{i}, i=1,2, \cdots, n
$$

Let $F C_{i}$ be a short run fixed cost of the $i$-th firm.

Then profit maximization problem of the $i$-th firm is formulated as:

$$
\max _{x_{i}}\left\{\pi_{i}\left(x_{i}\right)=p_{i} x_{i}-c_{i}\left(x_{i}\right)-F C_{i}\right\}
$$

We write down optimality conditions for problem (6).

$$
\pi_{i}^{\prime}\left(x_{i}\right)=p_{i}-3 a_{i} x_{i}^{2}-2 b_{i} x_{i}-c_{i}=0
$$

Solving this equation, we get the short run supply function of the $i$-th firm:

$$
x_{i}\left(p_{i}\right)=\frac{-b_{i}+\sqrt{b_{i}^{2}-3 a_{i}\left(c_{i}-p_{i}\right)}}{3 a_{i}}
$$

Taking into account demand and supply of the importing and exporting countries, we conclude that

$$
D \leq \sum_{i=1}^{n}\left(\frac{-b_{i}+\sqrt{b_{i}^{2}-3 a_{i}\left(c_{i}-p_{i}\right)}}{3 a_{i}}\right) .
$$

\section{Impact of an Export Credit Program (ECP)}

There are many works devoted to subsidy values ECPs. The present approach was developed in Baricell and Vercarmen (1994), Baron (1983), Hybery et al. [3].

A cost-benefit analysis was conducted by Fleid and Hill (1984). The option-pricing method was used by Dahl, Wilson, and Gustafson (1999), Dierson and Scherrick (1999), and Schich (1997) [3].

These research papers consider subsidy values provided by government-supported export credit programs. In these works, subsidy is considered as a cost savings to an importer which is a price discount on imports. Therefore, an importing country has benefits from an export credit program due to a cost savings. As a result, his decision how much to import is influenced by the cost savings. On the other hand, the cost saving may be considered as an additional income to the importing country.

It is assumed that the indirect benefits of an ECP, received by the consumer (importing country), can be considered as a fixed discount " $d$ " on his important payment [3]. The parameter " $d$ " is a measure to capture the indirect benefits arising from of the potential policy parameters of export credit programs. It is shown that " $d$ " is the difference of two present value streams [3] [4] [5] [6]. The first present value stream $\left(P V_{1}\right)$ is calculated under the scenario that there is no subsidy offered to the consumer. The second present value stream $\left(P V_{2}\right)$ deals with a subsidy offered to the consumer through an export credit program. Thus, the fixed discount rate " $d$ " is defined for each exporting country as:

$$
d_{i}=\frac{P V_{1}^{i}-P V_{2}^{i}}{P V_{1}} 100, i=1,2, \cdots, n
$$

It is clear that it the consumer receives benefits from an EPC, his budget con- 
straint is affected by the cost saving on the import payment. Thus, budget constraint of the consumer (importing country) has the following form:

$$
\sum_{i=1}^{n}\left(1-d_{i}\right) p_{i} x_{i} \leq C
$$

The discount rate $d_{i}$ is assumed to be

$$
0 \leq d_{i}<1, i=1,2, \cdots, n
$$

If $d_{i}=0$, it means that there is no discount on the import payment.

If $d_{i}=1$, then there is a full discount which means that variable $x_{i}$ does not play any role in the utility maximization problem. That is why it is important to consider the case for $0<d_{i}<1$.

We formulate again the utility maximization problem for the importing country (consumers) under ECP.

$$
\begin{gathered}
\max U_{i}\left(x_{1}, x_{2}, \cdots, x_{n}\right) \\
\sum_{i=1}^{n}\left(1-d_{i}\right) p_{i} x_{i} \leq C \\
\sum_{i=1}^{n} x_{i} \leq A
\end{gathered}
$$

The Marshallian demand functions for the consumer can be found by solving problem (9)-(11) by algorithm CGM.

\section{Export Supply and Non-Payment Risk under ECP}

We claim that the country's export supply is influenced by the country's export credit programs. We assume that the risk of not getting paid depends on the price $\left(p_{i}\right)$ of the exporting good. The price $\left(p_{i}\right)$ of getting paid is assumed to be a random variable. If $p_{i}$ is a negotiated price then $p_{i}$ is not a random variable. Introduce the following variables and notations

$\theta_{i}$ : credit score that explains non-payment of the export sales, $i=1,2, \cdots, n$.

$F_{i}\left(\theta_{i}\right)$ : cumulative probability distribution function of getting paid, $i=1,2, \cdots, n$.

$z_{i}$ : coverage level from an export insurance or guarantee policy such that $0 \leq z_{i} \leq 1$.

$\sigma_{i}$ : loading factor that reflects the administrate cost of providing the public guarantee or insurance scheme, $\bar{z}=1,2, \cdots, n$.

$E_{i}$ : expected value, $i=1,2, \cdots, n$.

$W_{i}$ : guarantee fee (or insurance premium rate) per unit of the exporting good $x_{i}$.

$$
W_{i}=W_{i}\left(z_{i}, \bar{F}_{i}, p_{i}\right)
$$

Compute the following statistics parameters.

$$
\begin{gathered}
E_{i}\left(p_{i} F_{i}\left(\theta_{i}\right)\right)=p_{i} E_{i}\left[F_{i}\left(\theta_{i}\right)\right]=p_{i} \bar{F}_{i}, \\
\operatorname{Var}\left[p_{i} F_{i}\left(\theta_{i}\right)\right]=E\left[\left\{p_{i} F_{i}\left(\theta_{i}\right)-E_{i}\left(p_{i} F_{i}\left(\theta_{i}\right)\right)\right\}^{2}\right]=p_{i}^{2} \sigma_{\theta_{i}}^{2}
\end{gathered}
$$


Stochastic profit functions of the exporting countries are:

$$
\begin{aligned}
\pi_{i}= & p_{i} F_{i}\left(\theta_{i}\right) x_{i}+z_{i} x_{i} p_{i}\left(1-F_{i}\left(\theta_{i}\right)\right)-\sigma_{i} W\left(z_{i}, \bar{F}_{i}, p_{i}\right) x_{i} \\
& -a x_{i}^{3}-b_{i} x_{i}^{2}-c_{i} x_{i}-F C_{i},
\end{aligned}
$$

The expected value and variance of the stochastic profit is:

$$
\begin{gathered}
E_{i}\left(\pi_{i}\right)=p_{i} \bar{F}_{i} x_{i}+z_{i} p_{i}\left(1-\bar{F}_{i}\right) x_{i}-\sigma_{i} W_{i}-a_{i} x_{i}^{3}-b_{i} x_{i}^{2}-c_{i} x_{i}-F C_{i}, \\
\operatorname{Var}_{i}\left(\pi_{i}\right)=\sigma_{\pi_{i}}^{2}=\left(1-z_{i}\right)^{2} \sigma_{\theta_{i}}^{2} x_{i}^{2} p_{i}^{2}, i=1,2, \cdots, n
\end{gathered}
$$

Assume that the firm is constant absolute risk aversion so its profit function [1] is

$$
\max _{x_{i}}\left\{\pi_{i}=E\left(\pi_{i}\right)-\frac{\lambda_{i}}{2} \sigma_{\pi_{i}}^{2}\right\},
$$

where $\lambda_{i}$ is a constant factor that measures the risk attitude of the representative firm. Write down problem (12) in the form:

$$
\begin{gathered}
\max _{x_{i}}\left\{\pi_{i}=p_{i} \bar{F}_{i} x_{i}+z_{i} p_{i}\left(1-\bar{F}_{i}\right) x_{i}-\sigma_{i} W_{i} x_{i}-a_{i} x_{i}^{3}-b_{i} x_{i}^{2}\right. \\
\left.-c_{i} x_{i}-F C_{i}-\frac{\lambda_{i}}{2}\left(1-z_{i}\right)^{2} \sigma_{\theta_{i}}^{2} x_{i}^{2} p_{i}^{2}\right\},
\end{gathered}
$$

The optimality condition for problem (13) is

$$
\frac{\mathrm{d} \pi_{i}}{\mathrm{~d} x_{i}}=0
$$

or equivalently,

$$
\begin{gathered}
p_{i} \bar{F}_{i} x_{i}+z_{i} p_{i}\left(1-\bar{F}_{i}\right)-\sigma_{i} W_{i}-3 a_{i} x_{i}^{2}-2 b_{i} x_{i}-c_{i}-\lambda_{i}\left(1-z_{i}\right)^{2} \sigma_{\theta_{i}}^{2} x_{i}^{2} p_{i}^{2}=0, \\
3 a_{i} \lambda_{i}^{2}+\left(2 b_{i}+\lambda_{i}\left(1-z_{i}\right)^{2} \sigma_{\theta_{i}}^{2} p_{i}^{2}\right) x_{i}+\left[c_{i}-p_{i} \bar{F}_{i}-z_{i} p_{i}\left(1-\bar{F}_{i}\right)+\sigma_{i} W_{i}\right]=0,
\end{gathered}
$$

Solving this quadratic equation, we find

$x_{i}=\frac{-\left(2 b_{i}+\lambda_{i}\left(1-z_{i}\right)^{2} \sigma_{\theta_{i}}^{2} x_{i}^{2} p_{i}^{2}\right)+\sqrt{\left(2 b_{i}+\lambda_{i}\left(1-z_{i}\right)^{2} \sigma_{\theta_{i}}^{2} p_{i}^{2}\right)^{2}-12 a_{i}\left(c_{i}-p_{i} \bar{F}_{i}-z_{i} p_{i}\left(1-\bar{F}_{i}\right)+\sigma_{i} W_{i}\right)}}{6 a_{i}}$

$x_{i}$ is an optimal export quantity of exporting country under risk of non-payment, $i=1,2, \cdots, n$.

We consider the following cases for Formula (15).

Case 1. $z_{i}=0$ and $\sigma_{i}=0$.

It means that self-insurer can be obtained by setting both coverage level and loading factor cost equal to zero. In this case Formula (15) has a form

$$
x_{1}=\frac{-\left(2 b_{i}+\lambda_{i} \sigma_{\theta_{i}}^{2} p_{i}^{2}\right)+\sqrt{\left(\sigma_{\theta_{i}}^{2}+\lambda_{i} \sigma_{\theta_{i}}^{2} p_{i}^{2}\right)^{2}+12 a_{i}\left(p_{i} \bar{F}_{i}-c_{i}\right)}}{6 a_{i}}
$$

Case 2. $\bar{F}_{i}=1$ and $\sigma_{\theta_{i}}^{2}=0$. It means that there is the full guarantee (insurance) coverage of assuring a certainly payment. Then Formula (15) has the form: 


$$
x_{i}=\frac{-\sigma_{\theta_{i}}^{2}+\sqrt{4 b_{i}^{2}+12 a_{i}\left(p_{i}-c_{i}-\sigma_{i} W_{i}\right)}}{6 a_{i}}
$$

In general, $\bar{F}_{i} \neq 1$ and $\sigma_{\theta_{i}}^{2} \neq 0$ since a default of the export payment is arisen from the importing country and the government agency of the exporting country cannot control the default.

Case 3: If there is no risk of export payment then we can set $z_{i}=1$. The optimal export quantity will be:

$$
x_{i}=\frac{-2 b_{i}+\sqrt{4 b_{i}^{2}+12 a_{i}\left(p_{i}-c_{i}-\sigma_{i} W_{i}\right)}}{6 a_{i}}
$$

Case 4: If there is a full guarantee (insurance) and no premium or loading cost then we have

$$
\sigma_{i}=0 .
$$

Then formula (15) has the form:

$x_{i}=\frac{-\left(2 b_{i}+\lambda_{i}\left(1-z_{i}\right)^{2} \sigma_{\theta}^{2} p_{1}^{2}\right)+\sqrt{2 b_{i}+\lambda_{i}\left(1-z_{i}\right)^{2} \sigma_{\theta_{i}}^{2} p_{i}^{2}-12 a_{i}\left(c_{i}-p_{i} \bar{F}_{i}-z_{i} p_{i}\left(1-\bar{F}_{i}\right)\right)}}{6 a_{i}}$

\section{Computational Results}

For computational simulation we considered six countries trade model with one importer for different discount rates for each country.

The utility function of the importing country was

$$
U\left(x_{1}, x_{2}, x_{3}, x_{4}, x_{5}\right)=A x_{1}^{0.012} x_{2}^{0.024} x_{3}^{0.028} x_{4}^{0.017} x_{5}^{0.015}
$$

with $C=300000, A=70000, p_{1}=5, p_{2}=20, p_{3}=35, p_{4}=16, p_{5}=30$ and $d_{1}=0.12, d_{2}=0.15, d_{3}=0.18, d_{4}=0,16, d_{4}=0,16$.

\begin{tabular}{cccc}
\hline Quantity of $x$ & $\begin{array}{c}\text { Actual value of } x \text { before } \\
\text { discount }\end{array}$ & $\begin{array}{c}\text { Values of } x \text { after } \\
\text { discount }\end{array}$ & Growth, \% \\
\hline 1 & 7500.0 & 8483.0 & 11.6 \\
2 & 3750.0 & 4382.8 & 14.4 \\
3 & 2500.0 & 3048.5 & 18.0 \\
4 & 3320.3 & 4005.1 & 17.1 \\
5 & 1562.5 & 1754.6 & 10.9 \\
\hline
\end{tabular}

\section{Conclusion}

We considered economic impact of export credit insurance for multi countries with one importer extending the papers [3] by Paul Pienstra-Munnicha, Calum Turkey and Wan W. Koo and [7] by Enkhbat R. and Tungalag N. Importer's [8] [9] utility function was Cobb-Douglas type and exporter's cost was a cubic function. The multi-counties partial trade models were developed to analyze the economic impact of the export credit insurance on trade flows. The export credit program helps to increase the exported quantity under certain assumptions. We 
have also shown that under stochastic factors the optimal export quantities can be computed analytically. In general, the paper aims to analyze economic impacts of ECP for multi-countries from a view of point microeconomic analysis. Also a computational experiment was implemented for five countries trade model.

\section{Acknowledgements}

This paper was supported by the project titled "Study on development of export credit program in Mongolia" of School of Business, National University of Mongolia.

\section{Conflicts of Interest}

The authors declare no conflicts of interest regarding the publication of this paper.

\section{References}

[1] Auboin, M. (2007) Boosting Trade Finance in Developing Countries: What Link with the WTO? World Trade Organization, Staff Working Paper ERSD-2007-04.

[2] Bertsekas, D.P. (2017) Nonlinear Programming. Athena Scientific, Nashua.

[3] Rienstra-Munnicha, P., Turvey, C. and Koo, W.W. (2006) A Theoretical Analysis of Economic Impacts of Export Credit Insurance and Guarantees. AAEA, Long Beach, California.

[4] Van Der Veer Koen, J.M. (2015) The Private Export Credit Insurance Effect on Trade. The Journal of Risk and Insurance, 82, 601-624. https://doi.org/10.1111/jori.12034

[5] Abraham. F. and Dewit, G. (2000) Export Promotion via Official Export Insurance. Open Economics Review, 11, 5-26. https://doi.org/10.1023/A:1008388511974

[6] Fitzgerald, B. and Monson, T. (1988) Export Credit and Insurance for Export Promotion. Finance and Development, 25, 53-55.

[7] Enkhbat, R. and Tungalag, N. (2018) Economic Impact of the Export Credit Insurance. Proceedings of 2018 China International Conference on Insurance and Risk Management, Baoding, 18-21 July 2018.

[8] Enkhbat, R., Undram, Ch. and Tungalag, N. (2018) The Export Credit Insurance Theoretical Research. Business and Innovation, 3.

[9] Undram, Ch. (2017) Developing of Export Credit Insurance Program in Mongolia. Business and Innovation, 3. 